\title{
QUIZ
}

CORRECT ANSWER TO THE QUIZ. CHECK YOUR DIAGNOSIS

\section{GOBLET CELL CARCINOID OF THE VERMIFORM APPENDIX - A CASE REPORT}

\author{
Konrad Ptaszyński ${ }^{1}$, Artur Bartczak ${ }^{1}$, Blanka Kołodziej ${ }^{2}$, Marek Szczepkowski ${ }^{3}$
}

\begin{abstract}
1Department of Pathology, Medical Centre for Postgraduate Education and Bielanski Hospital, Warsaw, Poland 2Department of Pathology, Lanssjukhuset Ryhov, Jonkoping, Sweden

3 Department of Rehabilitation, Józef Piłsudski University of Physical Education and Clinical Department of General and Colorectal Surgery, Bielanski Hospital, Warsaw
\end{abstract}

\begin{abstract}
Goblet cell carcinoid (GCC) is a rare neuroendocrine tumor of the vermiform appendix with uncertain clinical behavior. It was first described by Gagné and Subbuswamy in 1969 and 1974, respectively. The tumor occurs almost exclusively in the vermiform appendix. We present a case of a 60 -year-old female, who was referred to the Bielanski Hospital with signs and symptoms of acute appendicitis. Microscopic examination of the appendix showed features of acute appendicitis, however scattered groups of cells with clear cytoplasm as well as strands of single cells with no evidence of atypia were seen. The patient underwent a right hemicolectomy due to the diagnosis of GCC.
\end{abstract}

Key words: goblet cell carcinoid, neuroendocrine tumors, adenocarcinoid, appendix.

\section{Introduction}

Goblet cell carcinoid (GCC) is a rare tumor of the vermiform appendix with uncertain clinical behavior and presumed dual, neuroendocrine and intestinal goblet cell differentiation of the multipotent stem cells. However, histogenesis of GCC is not entirely clear. The tumor occurs in the appendix and is exceedingly rare in other parts of the gastrointestinal tract [1]. It was first recognized as a separate entity in 1969 by Gagné $e t$ al. and then designated as GCC by Subbuswamy et al. $[2,3]$. It was described in the literature under the names of adenocarcinoid, goblet cell tumor and mucinous adenocarcinoid [4]. Clinically, the lesion is frequently associated with appendicitis due to a diffuse growth pattern of the tumor involving the entire length of the appendix including the base as opposed to regular carcinoid which usually presents as a well-defined tumor of the appendiceal tip. This pattern of growth of GCC may be the cause of lumen occlusion and as a consequence, appendicitis [5]. According to analysis of SEER database, GCC occurs equally in men and women with a wide variation in age from 18 to 89 years, most commonly in Caucasians [6]. We present a case of a 60-year-old female with appendicitis and an incidental finding of GCC.

\section{Case report}

A 60-year-old woman was referred to the Bielanski Hospital with right lower quadrant pain, anorexia, nausea and vomiting. Physical examination revealed right lower quadrant abdominal tenderness and localized rebound tenderness. No palpable abdominal mass was present. Due to signs and symptoms typical of acute appendicitis, the patient underwent a simple appen- 
dectomy. Gross examination of the specimen showed a swollen appendix with an engorged serosa partly covered with fibrinous exudate. Microscopically the appendix showed a neutrophilic infiltrate of the entire thickness of its wall with an extension into the periappendiceal adipose tissue. In addition to the inflammatory cells, groups of clear cells were found predominantly in the muscularis propria, submucosa and subserosa of the appendix. Moreover, single clear cells were seen in the muscularis propria and groups of clear cells were seen in the mucosa and subserosa. The clear cells showed no significant atypia (Fig. 1). Immunohistochemical studies revealed positive staining of the tumor cells with antibodies against CKAE1/AE3, CK20, focal positive staining with the antibody against chromogranin B. There was a negative reaction with antibodies against $\mathrm{CK} 7$, synaptophysin and p53. Three percent of clear cells showed their nuclei stained with MIB1 (Ki-67) antibody (Fig. 1). The patient underwent a right hemicolectomy after the diagnosis of GCC has been made. No residual tumor was found in the bowel specimen. No evidence of disease has been seen in the six months of the follow up.

\section{Discussion}

Goblet cell carcinoid is a rare tumor of the vermiform appendix with uncertain clinical behavior and presumed dual, neuroendocrine and intestinal goblet cell differentiation Goblet Cell Carcinoid (GCC) occurs in the vermiform appendix equally in men and women in the age range of 18-89.

Tang et al. reviewed 63 cases of appendiceal lesions showing histological features of GCC in at least a portion of the tumor [7]. The authors included cases diagnosed originally as GCC, adenocarcinoid, mixed carcinoid adenocarcinoma, adenocarcinoma with neuroendocrine differentiation, adenocarcinoma of the signet ring cell type and carcinoid tumor. All cases were classified based on histological features of the primary lesion as typical GCC (group A), adenocarcinoma ex GCC, signet ring cell type (group B) and adenocarcinoma ex GCC, poorly differentiated adenocarcinoma type (group C). Cases showing group A pattern revealed goblet cells with no evidence of significant atypia arranged in well-defined clusters or linear structures especially appreciated in the muscularis propria. A minimal architectural distortion of the appendiceal wall can be seen and no desmoplasia is present. Extracellular mucin pools with degenerated tumoral cells are acceptable. Group B lesion has goblet cells or signet ring cells arranged in irregular large clusters, but no confluent sheets of cells, discohesive single file or single cell infiltrating pattern, significant cytologic atypia, and desmoplasia as well as destruction of the appendiceal wall. Group $C$ pattern has at least focal evidence of goblet cell morphology, a component ( $>1$ low power field or $1 \mathrm{~mm}^{2}$ ) not otherwise distinguishable from poorly differentiated adenocarcinoma, which may appear as either (a) gland forming, (b) confluent sheets or signet ring cells, or (c) undifferentiated carcinoma [7]. Our case showed regular groups of cells and strands of single cells with no evidence of atypia, infiltrating virtually the entire thickness of the appendiceal wall. Therefore, we classified the case as group A pattern, typical GCC.

Immunohistochemistry of GCC has been evaluated in several studies. The signet ring cells of GCC in most of the studies were positive for PAS, mucicarimine, pancytokeratin, CK20, CDX-2, MUC2 and CEA. They were focally positive for chromogranin $\mathrm{B}$ and synaptophysin. However $5 \%$ to $25 \%$ of cases were entirely negative for neuroendocrine markers [7-11]. Immunohistochemical studies of this case revealed positive staining with antibodies against CKAE1/AE3, CK20, focal positive staining with antibody against chromogranin $\mathrm{B}$. There was a negative reaction with antibodies against $\mathrm{CK} 7$, synaptophysin and $\mathrm{p} 53$. These results confirmed our diagnosis of GCC made based on HE histopathology.

As per Tang et al., p53 staining is negative in cases of typical GCC (class A) and adenocarcinoma ex GCC, signet ring cell type (class B). It is positive in adenocarcinoma ex GCC, poorly differentiated carcinoma type (class C) [7]. Clinical significance of MIB1 (Ki76) staining in GCC is controversial $[7,11]$.

Genetic studies of 16 cases of GCC revealed allelic loss of chromosomes 11q, 16q, and 18q in most of goblet cell carcinoids which are similar to those seen in ileal carcinoids and different from those of appendiceal adenocarcinoma. Results of this study suggest a putative common tumor suppressor gene in the pathogenesis of GCC and ileal carcinoids [12]. Tang et al. hypothesized that in the process of transformation of GCC to adenocarcinoma, additional genetic changes accumulate and facilitate the transformation [7].

Goblet cell carcinoids present most frequently with an associated appendicitis. It is believed that appendicitis is caused by a diffuse growth of the tumor In the entire length of the appendix, including the appendiceal base. Only in one study most of the cases of GCC presented with a palpable mass as a primary symptom and some cases presented initially at an advances clinical stage [7].

\section{References}

1. Gui X, Qin L, Gao ZH, et al. Goblet cell carcinoids at extraappendiceal locations of gastrointestinal tract: an underrecognized diagnostic pitfall. J Surg Oncol 2011; 103: 790-795.

2. Gagné F, Fortin P, Dufour V, Delage C. Tumors of the appendix associating histologic features of carcinoid and adenocarcinoma (article in French). Ann Anat Pathol (Paris) 1969; 14: 393-406.

3. Subbuswamy SG, Gibbs NM, Ross CF, Morson BC. Goblet cell carcinoid of the appendix. Cancer 1974; 34: 338-344. 

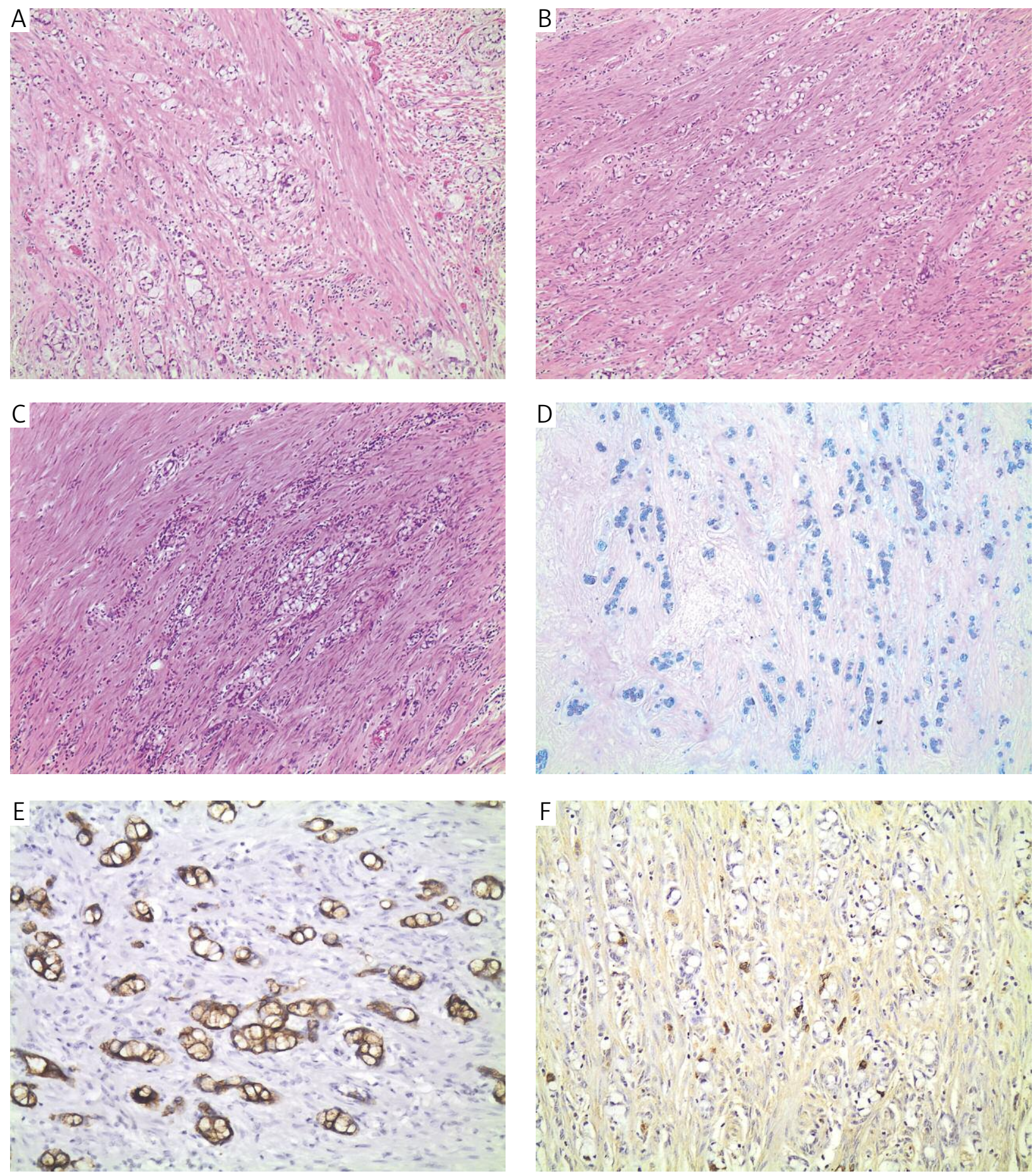

Fig. 1. A-D. Microscopic image of clear cells infiltrating the wall of the appendix (HE; $400 \times)$; E - CK20 stain of the tumor cells; F - Focal chromogranin stain can be seen

4. Isaacson P. Crypt cell carcinoma of the appendix (so-called adenocarcinoid tumor). Am J Surg Pathol 1984; 5: 213-224.

5. Connor SJ, Hanna GB, Frizelle FA. Appendiceal tumors: retrospective clinicopathologic analysis of appendiceal tumors from 7,970 appendectomies. Dis Colon Rectum 1998; 41: 75-80.

6. McCusker ME, Coté TR, Clegg LX, Sobin LH. Primary malignant neoplasms of the appendix: a population-based study from the surveillance, epidemiology and end-results program, 19731998. Cancer 2002; 94: 3307-3312.
7. Tang LH, Shia J, Soslow RA, et al. Pathologic classification and clinical behavior of the spectrum of goblet cell carcinoid tumors of the appendix. Am J Surg Pathol 2008; 32: 1429-1443.

8. Pahlavan PS, Kanthan R. Goblet cell carcinoid of the appendix. World J Surg Oncol 2005; 3: 36.

9. Kanthan R, Saxena A, Kanthan SC. Goblet cell carcinoids of the appendix: immunophenotype and ultrastructural study. Arch Pathol Lab Med 2001; 125: 386-390. 
10. Gulubova MV, Yovchev Y, Vlaykova T, et al. Application of light microscopical and ultrastructural immunohistochemistry in the study of goblet cell carcinoid in the appendix. World J Surg Oncol 2008; 6: 15.

11. Jiang Y, Long $\mathrm{H}$, Wang W, et al. Clinicopathological features and immunoexpression profiles of goblet cell carcinoid and typical carcinoid of the appendix. Pathol Oncol Res 2011; 17: 127132.

12. Stancu M, Wu TT, Wallace C, et al. Genetic alterations in goblet cell carcinoids of the vermiform appendix and comparison with gastrointestinal carcinoid tumors. Mod Pathol 2003; 16: 11891198.

\section{Address for correspondence}

Konrad Ptaszyński

Department of Pathology

Medical Centre for Postgraduate Education and Bielanski Hospital

ul. Marymoncka 99

02-813 Warsaw

e-mail: konrad.ptaszynski@cmkp.edu.pl 